\title{
Making Sense of a Most Popular Metaphor in Management: Towards a HedgeFox Scale for Cognitive Styles
}

\author{
Timo Meynhardt 1,2, ${ }^{\text {, Carolin Hermann }}{ }^{2}$ and Stefan Anderer ${ }^{1,3}$ \\ 1 HHL Leipzig Graduate School of Management, Jahnallee 59, 04109 Leipzig, Germany \\ 2 Center for Leadership and Values in Society, University of St. Gallen, Dufourstrasse 40a, \\ 9000 St. Gallen, Switzerland; carolin.hermann@unisg.ch \\ 3 Center for Advanced Studies in Management, HHL Leipzig Graduate School of Management, \\ Jahnallee 59, 04109 Leipzig, Germany; stefan.anderer@hhl.de \\ * Correspondence: timo.meynhardt@hhl.de
}

Received: 27 June 2017; Accepted: 3 September 2017; Published: 11 September 2017

\begin{abstract}
Research on cognitive style has gathered momentum over the past 40 years, especially with respect to learning, problem-solving, and decision-making. This investigation adapts Tetlock's hedgehog-fox scale for German-speaking respondents through three large-scale studies $(n=17,072)$ and examines the influence of cognitive style on employees' public value assessments of their employing organizations. Our data led us to propose a revised and more economical HedgeFox Scale. In contrast with Tetlock's findings, our results provide empirical and theoretical arguments for a two-factor structure. This shift in dimensionality affects the nature of the construct and aligns hedgehog-fox research with the latest developments in cognitive style research. Our results contribute to the ongoing interest in the dimensionality of cognitive styles and support the call for a more diverse picture. Finally, we provide recommendations for individuals and organizations.
\end{abstract}

Keywords: decision making; cognition; cognitive style; dimensionality; hedgehog-fox metaphor; public value

\section{Introduction}

From Tetlock (2005) long-term study of political experts' abilities to forecast future events, we know that cognitive style is associated with decision-making processes. To classify human mindsets, Tetlock uses the metaphor of the hedgehog and the fox, as introduced by the Greek poet Archilochus and employed by the Russian-British philosopher Isaiah Berlin (Berlin 1997). Confronted with a situation calling for a judgment or decision, hedgehogs have a high need for cognitive closure, prefer clarity, and favor one universal organizing principle. Foxes allow for ambiguity and are open to different opinions and new ideas. Tetlock's study showed that foxes could predict future (political) events better than hedgehogs. Foxes seem to be able to better deal with complexity, while hedgehogs neglect important environmental variables in their judgments.

The influence of cognitive styles has become evident not only in relation to political judgment, as investigations have shown that the ways in which we perceive information and derive meaning from it are also relevant for decision-making, problem-solving, learning, creativity, and the support of different values (Hayes and Allinson 1998; Kirton 1976; Spicer and Sadler-Smith 2005; Puccio et al. 1995; Tetlock 2000; Van Den Broeck et al. 2003).

Tetlock's distinction has drawn much attention, particularly in management practice (Gomez and Meynhardt 2012; Silver 2015; Collins 2001; Kay 2011; Mitchell and Tetlock 2010). In their study with top managers, Gomez and Meynhardt (2012) used a cognitive style perspective to analyze 
how managers differ in their value awareness, and their results provide reason to assume that cognitive style influences how individuals perceive organizations' roles in society. Those authors provide the basis for investigating cognitive style differences concerning public value evaluations-that is, an organization's contribution to society at large.

Tetlock's cognitive style measure allows one to depict how individuals deal with ambiguity and complex information, both of which should be highly relevant for public value assessments. Public value differs from other concepts like sustainability or corporate social responsibility in that it allows a holistic view of organizations that considers not only financial outcomes but also the organization's contribution to social cohesion and quality of life as well as its moral behavior. Because we are interested in learning about factors that might be relevant for public value assessments, we build on the results of Gomez and Meynhardt (2012) study and analyze the relationship between cognitive styles and public value assessments. Since the public value concept calls for a multidimensional assessment of organizational action beyond merely financial aspects, investigating the interplay between cognitive style and public value makes it possible for us to find out how individuals differ with respect to their openness to integrate multiple viewpoints into their assessment and regarding focused assessment based on some key variables. Thus, Tetlock's cognitive style instrument is a promising tool for our research because it portrays how people approach complex information.

According to Tetlock (2005), individuals prefer either hedgehog-like or fox-like ways of thinking. But does this black-white dichotomy reflect reality, or is there some flexibility in how people can use cognitive styles? Could a hedgehog learn to make better predictions and acquire fox-like characteristics for more balanced judgment or decision-making? To advance Tetlock's perspective, it is necessary to reflect on, and empirically test, his ideas in light of recent findings from cognitive styles research.

The ongoing interest in the dimensionality of cognitive styles (Hodgkinson and Sadler-Smith 2003; Goodenough and Witkin 1977; Akinci and Sadler-Smith 2013; Kozhevnikov 2007) and the expanding use of the hedgehog-fox scale in management practice give cause to thoroughly investigate the reliability and validity of Tetlock's instrument in settings other than political science. In addition, the original scale has not been revised empirically. We apply the scale in Germany and the German-speaking area of Switzerland and test it as a predictor of public value assessments, and we examine whether the conceptual structure can be confirmed.

Our empirical validation using three large-scale studies $(n=17,072)$ of the proposed hedgehog-fox dichotomy indicates that this classification is oversimplified. Our results show that individuals can display both cognitive styles, and the findings lead to a better understanding of cognitive style diversity. The results directly affect ideas about individual judgment and organizational decision-making and learning, as well as the development of training measures. This paper's main contribution is therefore a re-consideration of Tetlock's original dichotomy toward a more nuanced interpretation of the construct's nature.

In the remaining article, we provide a definition of cognitive styles and highlight their significance for judgments and decision-making. Further, we survey the current developments in cognitive style research by focusing on the nature and structure of cognitive styles and assumptions about styles on a metacognitive level. We then underline the relevance of the hedgehog-fox measure for management and the context of public value. Finally, we derive implications for Tetlock's cognitive style instrument and empirically test them. Drawing on the results, we provide conclusions for theory and practice, and highlight perspectives for future research.

\section{Theoretical Background}

Cognitive theories are a promising approach to explaining individuals' decision-making (LeFebvre and Franke 2013). These theories focus on human information processing rather than rational models of decision-making, thus increasing our understanding of information-processing 
modes involved in the decision-making process (LeFebvre and Franke 2013). These different modes of information processing are called cognitive styles.

\subsection{A Definition of Cognitive Styles}

Cognitive styles "refer to individual differences in how we perceive, think, solve problems, learn, relate to others" (Witkin et al. 1977, p. 29). This definition is based on the notion that individuals have a mental representation — or mental map —of the world that helps them order and make sense of new information (Walsh 1995). More recently, researchers specified cognitive styles as "patterns of adaptation to the external world; these patterns develop in part on the basis of innate predispositions, but are modified as a result of changing environmental demands" (Kozhevnikov et al. 2014, p. 4). This perspective strengthens the relational view, adding the aspect of stability. It also draws attention to individual predispositions, the influence of environment, and the plasticity of cognitive styles.

Engagement with cognitive styles dates back at least to Jung (1923) theory of psychological types and peaked in the 1950s and 1960s in an effort to connect differences in perception with personality (Sternberg and Grigorenko 1997). However, during the late 1970s, psychological research on cognitive styles decreased, mainly because of numerous, largely overlapping cognitive style dimensions, the absence of a theoretical foundation, and the lack of attempts to integrate the dimensions (Kozhevnikov 2007).

As a result, scholars have used various style labels to describe individual information-processing preferences. Besides cognitive style, labels include learning style, thinking style, and the more general intellectual style (Zhang et al. 2011). In addition, a variety of style dimensions have been introduced (Hayes and Allinson 1994), pointing to the complexity and vastness of cognitive style research.

Cognitive styles exert a fundamental influence on individual and organizational behavior (Hayes and Allinson 1994; Sadler-Smith and Badger 1998) and research has revealed that cognitive styles help explain individual distinctions in human behaviors and performance (Riding 2011). A review of several studies concludes that the relationship between cognitive styles and abilities is complex, that styles explain additional variance in human performance above intelligence and personality, and that abilities and styles are related (Zhang and Sternberg 2012). However, knowledge about the etiology of styles is inadequate for comprehensively explaining their formation (Mandelman and Grigorenko 2011).

\subsection{The Significance of Cognitive Styles}

Numerous studies link cognitive styles to decision-making (Tetlock 2005; Kozhevnikov 2007; Betsch and Kunz 2008; Armstrong et al. 2012). In particular, an analysis of 438 papers on cognitive styles in the management context between 1969 and 2009 indicates that cognitive styles can be very relevant to the business and management research fields, not only for decision-making but also for teamwork, learning, and creativity (Armstrong et al. 2012).

Despite their shortcomings, concepts of cognitive styles have a high practical relevance, which is reflected by the number of cognitive style instruments (Armstrong et al. 2012). Instruments such as the Myers-Briggs Type Indicator (MBTI) (Briggs and Myers 1995), the Agor Intuitive Management survey (AIM) (Agor 1989), or the Kirton Adaption Innovation Inventory (KAI) (Kirton 1976) are frequently used to investigate the influence of cognitive styles on decision-making (Kozhevnikov 2007).

\subsection{The Nature and Structure of Cognitive Styles}

Many cognitive styles have been conceptualized as unitary and have been measured with unidimensional instruments (Hodgkinson and Sadler-Smith 2003; Allinson and Hayes 1996). As a result of the multiplicity of cognitive style dimensions, investigators have made various attempts to unite current cognitive style theories (Moskvina and Kozhevnikov 2011), and have introduced some unifying frameworks (Allinson and Hayes 1996). 
Further, findings that individuals could change their cognitive style contingent on situational demands have forced researchers to question the dimensionality of cognitive styles and sometimes to suggest enlarging the concept into more dimensions (Kozhevnikov 2007; Kozhevnikov et al. 2014), leading to discussion about whether cognitive styles must be conceptualized as more complex (Hodgkinson and Sadler-Smith 2003).

A widely recognized endeavor to coordinate the various cognitive styles was that of Allinson and Hayes (1996). Their study had two objectives. The first was to develop an instrument for managers and professionals to assess cognitive styles in sizable organizational settings- the result was the Cognitive Style Index (CSI). The second was to empirically substantiate a unitary view on cognitive style, suggesting that all cognitive styles could be cut down to one analytical/intuitive dimension. This assumption resulted from a review of the work of several cognitive style researchers who argued for one dimension that underlies all facets of cognitive style, particularly arguing against split-brain studies that propose a specialization tendency of the brain hemispheres, with the right hemisphere specializing in intuition and the left in analysis.

However, theoretical and methodological concerns have led Allinson and Hayes' proposition of the unitary nature of cognitive styles to be called into question. For instance, Hodgkinson and Sadler-Smith (2003) argue that a unitary conceptualization does no justice to the complexity of information-processing. They reason that intuitive and analytic information-processing are necessary for different functions and are therefore independent cognitive systems. Referring to dual-process theories, specifically Epstein's Cognitive-Experiential Self-Theory (CEST) (Epstein 2003), they suggest that analysis and intuition are separate, unipolar information-processing modes. Their methodological criticism concerns the item parceling technique, which yielded to heterogeneous parcels that might have fostered the unifactorial factor solution, and the factor extraction approach, which in their opinion lacks confirmatory procedures.

The results of Hodgkinson and Sadler-Smith's review of the CSI suggest two separate correlated factors that contradict the conceptualization of the CSI as unifactorial. They propose that analytical and intuitive processes are independent dimensions that fulfill different functions, and recent studies support this conceptualization (Akinci and Sadler-Smith 2013; Hodgkinson et al. 2009; Wang et al. 2017). In their meta-analysis, Wang et al. (2017) show the independence of the analysis and intuition constructs. These results are underpinned by Simon (1987, p. 61), who states:

It is doubtful that we will find two types of manager (at least, of good managers), one of whom relies almost exclusively on intuition, the other on analytic techniques. More likely, we will find a continuum of decision-making styles involving an intimate combination of the two kinds of skill. We will likely also find that the nature of the problem to be solved will be a principal determinant of the mix.

Thus the environment shapes the use of cognitive styles (Simon 1987) and different situations and our experiences can influence that use (Hayes and Allinson 1998).

A more recent trend in this research field is to connect cognitive styles with metacognitive functioning. Individuals differ in their abilities to control their cognitive functioning at a metacognitive level and to adjust their cognitive style preferences (Kozhevnikov 2007). Higher-order metastyles, which correspond to the idea of multiple cognitive style levels, may regulate inferior styles and explain why some individuals are flexible in their use of styles (Kozhevnikov 2007; Moskvina and Kozhevnikov 2011). Metastyles act at a higher metacognitive information-processing level (Kozhevnikov et al. 2014). For instance, the supra-ordinate mobility-fixity dimension is considered to be a metastyle that enables individuals who are mobile to choose between different style preferences (Moskvina and Kozhevnikov 2011).

In sum, the results of the various attempts to unite the variety of cognitive styles underline that cognitive styles are not detached from each other and do not belong to a single underlying dimension (Moskvina and Kozhevnikov 2011). 
These developments on cognitive style conceptualization and flexibility cast doubt on Tetlock's bipolar conceptualization of cognitive style as reflected in his style of reasoning scale. The instrument relies mainly on the Need for Cognitive Closure Scale (NFCS) (Webster and Kruglanski 1994; Neuberg et al. 1997) but the unidimensional conceptualization of the NFCS has been questioned as research results have revealed a multifactorial structure, suggesting a two-factor solution (Neuberg et al. 1997). Tetlock himself has reported a second factor, which he calls decisiveness, but does not elaborate on it.

\subsection{The Relevance of the Hedgehog-Fox Instrument for Management}

The hedgehog-fox metaphor has become widely acknowledged beyond political science, especially in the management field and in research into human behavior (Gomez and Meynhardt 2012; Silver 2015; Collins 2001; Kay 2011; Mitchell and Tetlock 2010). Management executives operate in fast-moving and complex environments and are confronted with mega-trends (Rüegg-Stürm 2002) that change the economy and business models. The intensive use of the metaphor in the field of management is a case in point for structural features similar to Tetlock's field of application.

Since cognitive style is a fundamental human property and not subject to a specific field of application, Tetlock's primary criterion is the complexity of individuals' environment and the qualitatively different ways of approaching it. For instance, Mitchell and Tetlock (2010) argue that judicial opinions are influenced by cognitive style and judges with a preference for the fox pole might be more integratively complex individuals who see problems from different perspectives and consider a variety of information and interests. Judges with a preference for the hedgehog pole might be less integratively complex individuals who concentrate on a few key pieces of evidence and do not seek compromise. As another example, a study of executives found that top managers differ in their awareness of their organizations' contribution to society (public value), depending on their preferred cognitive style (Gomez and Meynhardt 2012). That study used the hedgehog-fox metaphor to differentiate between executives who tend to apply universal principles and overestimate their knowledge about the world (hedgehogs) and those who tend to appreciate plurality and allow for alternatives (foxes). The study's authors consider the openness to alternative views and multiple realities to be basic characteristic of value awareness, which is essential if one is to reflect on the societal impacts of organizations. More than $60 \%$ of the top managers displayed hedgehog-like characteristics and over-estimated their organizations' roles in society.

Our aim is to analyze whether the fox-hedgehog difference manifests in respondents across different occupations and positions with respect to their public value assessment of organizations.

To the present day, there has not been a validated German version of Tetlock's scale. For this reason, we want to provide a German version of the instrument and test its validity for the German language area.

We focus on public value because it conceptualizes how people perceive and interpret an organization's contribution to the common good. Since its inception (Moore 1995) the public value concept has become an important topic for businesses, public administrations, and non-governmental organizations (NGOs). A widely held perception is that a much deeper understanding is needed of how people construct public value at the individual level (Meynhardt 2015), especially as which psychological mechanisms drive the respective perception and interpretation remains an open question. Public value "is situated in relationships between the individual and 'society,' founded in individuals, constituted by subjective evaluations against basic needs, activated by and realized in emotional-motivational states, and produced and reproduced in experience-intense practices" (Meynhardt 2009, p. 212). Cognitive style is a natural candidate for a much-needed micro-foundation of public value assessments. 


\subsection{Dimensionality and Metaphors in Practice}

Besides the theoretical considerations in cognitive style research, dimensionality has strong implications for practical application. The question of dimensionality is closely related to the nature and the use of the hedgehog-fox metaphor. In their seminal book on metaphors, Lakoff and Johnson (2003) argue, "In allowing us to focus on one aspect of a concept [ . . ] a metaphorical concept can keep us from focusing on other aspects of the concept that are inconsistent with that metaphor" (2003, p. 10). In other words, metaphors systematically highlight and hide. A one-dimensional structure with mutually exclusive qualities has different implications for an individual and on an organizational level than a conception of parallel coexistent dimensions.

In light of the current views of the cognitive styles' very idea (unipolar vs. bipolar) and their frequent use in management practice, we analyze the factor structure of Tetlock's hedgehog-fox measure. We also test its validity for German-speaking respondents and investigate its influence on public value assessments of respondents from different professions and positions.

\section{Data and Methods}

\subsection{Participants and Procedure}

We collected all our data in the course of the Public Value Atlas Project, which began in 2014. Drawing on representative surveys, the Public Value Atlas provides rankings of the public value of various companies and organizations in Switzerland (Public Value Atlas Switzerland $(2014,2015)$ ) and Germany (Public Value Atlas Germany 2015). For this survey, each respondent evaluated a maximum of six organizations from different industries concerning their public value.

We used three public value studies to validate the hedgehog-fox scale. Study 1 was carried out in Switzerland and was used for scale development. Studies 2 and 3 were conducted in Switzerland and Germany and were used to confirm our adapted scale.

\subsubsection{Study 1}

In Study 1, a total of 4483 individuals, aged between 18 and $88(\mathrm{M}=47.51$ years, SD $=16.03)$ were surveyed. According to the current data of the Swiss Federal Statistical Office, the sample was representative of the population in terms of gender, age, education level, and region of residence in the German-speaking area of Switzerland. Given some screening questions of the questionnaire, minor deviations in the representative distribution resulted with regard to age $( \pm 3 \%)$, region of residence $( \pm 5 \%)$ and education $( \pm 5 \%)$. For gender, the quota was reached. We collected data via an online survey over a three-week period between February and March 2014. The sample consisted of 2277 female and 2206 male participants. All respondents were registered participants of an online panel of a Swiss market research bureau and subject to consistent quality assurance. A subsample of 2245 was randomly selected for further analysis. This subsample comprised 1088 men and 1157 women, of which $21 \%$ $(n=480)$ had a leadership responsibility and were employed across different industries such as the automotive, education, finance, healthcare, and finance industries.

\subsubsection{Study 2}

Study 2 took place within four weeks in June and July 2015. A total of 5052 people, aged between 18 and 90 years $(\mathrm{M}=47.93$ years, $\mathrm{SD}=16.49)$, from the German-speaking area of Switzerland completed an online survey. Of these, $50.2 \%(n=2537)$ were women and $49.8 \%(n=2515)$ were men. As in Study 1, the respondents were part of an online panel of a Swiss market research bureau. They were randomly chosen as a representative sample of the population in the German-speaking area of Switzerland, in accordance with the current data of the Swiss Federal Statistical Office concerning gender, age, education level, and residential area. As a result of questionnaire-specific screening categories, only minor deviations occurred in the representative distribution concerning age $( \pm 3 \%)$ and region of residence $( \pm 4 \%)$. The quotas with regard to gender and education were maintained 
without deviations. Participants had various economic, educational, and occupational backgrounds. Further, $64.8 \%(n=3275)$ of the sample were employed, with $63.3 \%(n=2072)$ working full-time and $39.4 \%(n=1291)$ holding a leadership responsibility.

\subsubsection{Study 3}

For Study 3, we surveyed 7537 people in Germany over a three-week period between July and August 2015. The respondents were aged between 19 and $91(M=53.85$ years, $S D=14.17)$. Of these, $45.0 \%(n=3514)$ were women and $55.0 \%(n=4288)$ were men. The respondents were all registered panelists of a German market research bureau. In accordance with the current data of the Federal Statistical Office of Germany, they were a representative randomly selected sample from a panel with 30,000 participants in Germany. They participated in an online survey and had a wide range of educational backgrounds; $58.4 \%(n=4555)$ were employed and worked in various industries, of which $75.2 \%(n=3461)$ worked full-time and $36.4 \%(n=1657)$ had leadership responsibilities.

\subsection{Measures}

\subsubsection{Cognitive Style}

We applied Tetlock's 13-item hedgehog-fox scale to assess cognitive styles on a six-point Likert scale $(1=$ totally disagree to $6=$ totally agree). The scale is based on several subscales of the NFCS (Kruglanski et al. 1993). The hedgehog-fox scale reflects decisiveness (e.g., "I usually make important decisions quickly and confidently"), ambiguity (e.g., "When considering most conflict situations, I can usually see how both sides could be right"), order (e.g., "Having clear rules and order at work is essential for success"), and closed-mindedness (e.g., "I prefer interacting with people whose opinions are very different to my own" (reversed)). Further, the scale is built on items of integrative complexity (e.g., "Scholars are usually at greater risk of exaggerating how complex the world is than they are of underestimating how complex it is"). The integrative complexity measure assesses the extent to which respondents are able to differentiate (recognize different perspectives or dimensions of stimuli) and integrate (form connections between perspectives or dimensions of stimuli) information (Guttieri et al. 1995). Integrative complex individuals integrate multiple perspectives into their reasoning, while integrative simple individuals prefer only a few key pieces of information. To adapt the scale for the German-speaking countries, we did a double-blind back-translation of the items (Harkness and Schoua-Glusberg 1998). In this procedure, the items are translated into the target language. This version is translated back into the original language so that the two versions can be compared with each other (Harkness et al. 2004). An independent bilingual translator carried out the back-translation into English. The researchers and the translator subsequently discussed the two resulting versions of the items. The German translation was adapted where weaknesses were detected within this procedure. We modified two of the 13 items owing to the different study context. Whereas Tetlock used the scale in the political context, this study's research context was the field of public value (Meynhardt 2009). Thus, we adapted the original items from political reasoning to common good reasoning (e.g., instead of "Politics is more cloudlike than clocklike," we re-worded the item to "I think the common good is more cloudlike than clocklike"), and we replaced one item- "We are closer than many think to achieving parsimonious explanations of politics"—with "The common good is determined by a few simple factors."

\subsubsection{Public Value}

Job-holders evaluated the public value of their employing organization with validated single-item measures for each public value dimension (Meynhardt and Bartholomes 2011). Respondents assessed their organizations according to the four public value dimensions of task fulfilment ("The organization I work for does good work in its core business"), social cohesion ("The organization I work for contributes to social cohesion in Switzerland"—or in Germany, respectively), quality of life 
("The organization I work for contributes to quality of life in Switzerland" - or in Germany, respectively), and morality ("The organization I work for behaves decently"). Answers were given along a six-point Likert scale $(1=$ disagree to $6=$ agree $)$.

\section{Analysis and Findings}

\subsection{Scale Development}

In Study 1, we chose a two-step procedure to meet established methodological standards (Brown 2006) and examine the factor structure. To conduct an exploratory factor analysis (EFA) in a first step and a confirmatory factor analysis (CFA) in a second step, we divided the representative Swiss sample into halves. Four factors led us to revise the initial scale properties in this procedure. First, the general interest in the structure of cognitive style raised questions about the uni-dimensionality. Second, the particular set of items had already been found to have two underlying epistemic motives. Third, the forward / backward translation process demanded a thorough review. Fourth, the narrow population used in Tetlock's scale development raised doubts about its generalizability.

In a first analysis, we ran the EFA with one half of the respondents (subsample 1: $n=2238$ ). We used the second half (subsample 2: $n=2245$ ) to confirm the factor structure and to run further analyses.

\subsection{Exploratory Factor Analysis (EFA)}

Prior to the analysis, Kaiser-Meyer-Olkin measures $(\mathrm{KMO}=0.75)$ confirmed the sampling adequacy and Bartlett's test of sphericity $\left(\chi^{2}=3039.56 \mathrm{df}=78, p<0.01\right)$ indicated sufficiently large correlations between the items to run a principal component analysis as an EFA. An EFA differentiates between explained and residual variance. We considered various criteria to explore the number of factors to retain, such as eigenvalues greater than one, a scree plot test, and theoretical considerations. We chose varimax with Kaiser normalization as the rotation method.

In contrast to Tetlock's results (2005), the rotated solution revealed a three-factor structure (see Table 1). As the narrowly defined population in Tetlock's inquiry (political experts) was compared with a representative sample of the population of Switzerland, neither the mismatch nor the inconclusive factor structure was surprising.

Table 1. Results of the Exploratory Factor Analysis for the Fox-Hedgehog Scale (adopted from Tetlock 2005).

\begin{tabular}{|c|c|c|c|}
\hline \multirow{2}{*}{ Item } & \multicolumn{3}{|c|}{ Rotated Factor Loadings } \\
\hline & Factor 1 & Factor 2 & Factor 3 \\
\hline I dislike questions that can be answered in many different ways. & 0.63 & 0.19 & -0.24 \\
\hline When trying to solve a problem, I often see so many possible options that it is confusing. & 0.62 & -0.37 & 0.19 \\
\hline $\begin{array}{l}\text { Scholars are usually at greater risk of exaggerating how complex the world is than they are } \\
\text { of underestimating how complex it is. }\end{array}$ & 0.58 & 0.34 & -0.03 \\
\hline The common good is determined by a few simple factors. & 0.45 & 0.35 & 0.02 \\
\hline $\begin{array}{l}\text { In a famous essay, the philosopher Isaiah Berlin classified intellectuals as hedgehogs or } \\
\text { foxes. The hedgehog knows one big thing and tries to explain as much as possible within } \\
\text { that conceptual framework, whereas the fox knows many small things and is content to } \\
\text { improvise explanations on a case-by-case basis. I see myself as a fox. }\end{array}$ & 0.44 & 0.02 & 0.18 \\
\hline $\begin{array}{l}\text { The more common error in decision-making is to abandon good ideas too quickly, not to } \\
\text { stick with bad ideas too long. }\end{array}$ & 0.44 & 0.29 & 0.20 \\
\hline I usually make important decisions quickly and confidently. & -0.01 & 0.74 & 0.16 \\
\hline It is annoying to listen to someone who cannot seem to make up his or her mind. & 0.09 & 0.68 & 0.01 \\
\hline Having clear rules and order at work is essential for success. & 0.28 & 0.52 & 0.09 \\
\hline When considering most conflict situations, I can usually see how both sides could be right. & 0.06 & -0.04 & 0.73 \\
\hline $\begin{array}{l}\text { Even after I have made up my mind about something, I am always eager to consider a } \\
\text { different opinion. }\end{array}$ & 0.01 & 0.13 & 0.69 \\
\hline I prefer interacting with people whose opinions are very different from my own. & 0.07 & 0.28 & 0.55 \\
\hline $\begin{array}{l}\text { I think the common good is more cloudlike than clocklike ("cloudlike" meaning inherently } \\
\text { unpredictable; "clocklike" meaning perfectly predictable if we have adequate knowledge). }\end{array}$ & 0.38 & -0.11 & 0.39 \\
\hline Eigenvalue & 2.69 & 1.46 & 1.35 \\
\hline Variance \% & 20.71 & 11.25 & 10.35 \\
\hline Cronbach's $\alpha$ & 0.45 & 0.55 & 0.51 \\
\hline
\end{tabular}

Notes: Extraction method: principal component analysis. Rotation method: Varimax with Kaiser normalization. 
Since an EFA is an iterative process and an item-reducing technique, the initial 13-item scale was the basis for further adaptations. We eliminated items with substantial cross-loadings above 0.30 and items with factor loadings below 0.50 (Baggozzi and Yi 1998). The observed cross-loadings not only violated methodological standards, but, from a theoretical perspective, the factors represented opposing constructs.

Four items did not meet the standard of item-factor loading above 0.50 . Two items exhibited similar loadings on factors 1 and 2, and were therefore removed. Thus, we ran further analyses with seven items. A second test of the scale's factorial structure revealed a stable solution represented by two factors explaining $47.02 \%$ of the variance. The assumptions were also met, since satisfying values were exhibited in the tests $(\mathrm{KMO}=0.66$; Bartlett's tests of sphericity $=1306.95, \mathrm{df}=21, p<0.01)$. Table 2 displays the descriptive statistics and factor loadings of the remaining seven items.

Table 2. Results of the Exploratory Factor Analysis.

\begin{tabular}{|c|c|c|}
\hline \multirow{2}{*}{ Item } & \multicolumn{2}{|c|}{ Rotated Factor Loadings } \\
\hline & Hedgehogness & Foxiness \\
\hline $\begin{array}{l}\text { It is annoying to listen to someone who cannot seem to make up } \\
\text { his or her mind. }\end{array}$ & 0.72 & 0.06 \\
\hline Having clear rules and order at work is essential for success. & 0.65 & 0.16 \\
\hline I usually make important decisions quickly and confidently. & 0.62 & 0.24 \\
\hline I dislike questions that can be answered in many different ways. & 0.58 & -0.22 \\
\hline $\begin{array}{l}\text { Even after I have made up my mind about something, I am } \\
\text { always eager to consider a different opinion. }\end{array}$ & 0.04 & 0.73 \\
\hline $\begin{array}{l}\text { When considering most conflict situations, I can usually see how } \\
\text { both sides could be right. }\end{array}$ & -0.05 & 0.72 \\
\hline $\begin{array}{l}\text { I prefer interacting with people whose opinions are very } \\
\text { different from my own. }\end{array}$ & 0.22 & 0.62 \\
\hline Eigenvalue & 1.95 & 1.34 \\
\hline Variance \% & 27.90 & 19.12 \\
\hline Cronbach's $\alpha$ & 0.53 & 0.51 \\
\hline
\end{tabular}

Notes: Extraction method: principal component analysis. Rotation method: Varimax with Kaiser normalization.

Four items loaded only on the first factor and explained $28 \%$ of the variance with Cronbach's $\alpha=0.53$. The second factor included three items and explained $19 \%$ of the variance, while Cronbach's $\alpha$ was 0.51 .

Unlike the adapted scale, the results of the EFA clearly suggested a two-factor structure of cognitive style measurement with adequate scale properties, which enabled us to formulate an alternative conception to the one-factorial fox-hedgehog.

\subsection{Confirmatory Factor Analysis (CFA)}

Applying the software AMOS, we then tested this model on the subsample of 2245 respondents in a structural equation model and against an alternative one-factor model. To determine the models' quality, we chose several indices as criteria for a good fit.

First, we report an absolute fit index that observes the fit of the data with an a priori specified model. Model chi-square $\left(\chi^{2}\right)$, which evaluates the overall fit of the data, is traditionally a very popular index. In addition, we considered the root mean square error of approximation (RMSEA). According to McDonald and Ho (2002), who surveyed articles on structural equation models in high impact psychological journals between 1995 and 1997, a good fit is 0.05 and a moderate fit is 0.08 . The two-factor model (hedgehogness and foxiness) obtained a significant $\chi^{2}$ value, and a RMSEA of 0.06 indicated a better fit than the one-factor model, which did not show an acceptable model fit with RMSEA of 0.10 (McDonald and Ho 2002).

Second, we observed a relative fit index that was not based on a $\chi^{2}$ test. We chose the comparative fit index (CFI) because it assumes uncorrelated latent variables, which fits our analyses so far. The CFI 
compares the sample's covariance matrix with a null model (Hooper et al. 2008). An acceptable fit is achieved when the CFI is greater than 0.90 (McDonald and Ho 2002). Only the two-factor solution reached this level (0.94). Table 3 shows the results.

Table 3. Results of Confirmatory Factor Analysis (Seven Items) for Study 1 (Subsample 2: $n=2245$ ), AMOS Model Fit Indices.

\begin{tabular}{ccccccc}
\hline Model & Description & $\chi^{2}$ & df & $\chi^{2} / \mathbf{d f}$ & RMSEA & CFI \\
\hline Model 1 & One-factor model & $254.22^{* *}$ & 12 & 21.19 & 0.10 & 0.81 \\
Model 2 & Two-factor model & $85.61^{* *}$ & 11 & 7.78 & 0.06 & 0.94 \\
\hline Notes: RMSEA & Root mean square error of approximation; CFI $=$ comparative fit index. ${ }^{* *} p<0.01$.
\end{tabular}

The item "I dislike questions that can be answered in many different ways" showed low loadings on the hedgehogness factor. Removing the item improved the two-factor solution's model fit, with a lower RMSEA value (0.04) and a better CFI (0.98). Table 4 shows the results of the confirmatory factor analysis for the remaining six items.

Table 4. Results of the Confirmatory Factor Analysis (Six Items) for Study 1 (Subsample 2: $n=2245$ ).

\begin{tabular}{lll}
\hline \multirow{2}{*}{ Item } & \multicolumn{2}{l}{ Rotated Factor Loadings } \\
\cline { 2 - 3 } & Hedgehogness & Foxiness \\
\hline $\begin{array}{l}\text { It is annoying to listen to someone who cannot seem to make up his } \\
\text { or her mind. }\end{array}$ & 0.75 & -0.02 \\
$\begin{array}{l}\text { I think that having clear rules and order at work is essential } \\
\text { for success. }\end{array}$ & 0.65 & 0.15 \\
$\begin{array}{l}\text { I usually make important decisions quickly and confidently. } \\
\text { Even after I have made up my mind about something, I am always } \\
\text { eager to consider a different opinion. }\end{array}$ & 0.75 & 0.09 \\
$\begin{array}{l}\text { When considering most conflict situations, I can usually see how } \\
\text { both sides could be right. }\end{array}$ & -0.03 & 0.74 \\
$\begin{array}{l}\text { I prefer interacting with people whose opinions are very different } \\
\text { from my own. }\end{array}$ & 0.23 & 0.73 \\
$\begin{array}{l}\text { Eigenvalue } \\
\text { Variance } \%\end{array}$ & 1.87 & 0.64 \\
Cronbach's $\alpha$ & 31.21 & 1.24 \\
\hline
\end{tabular}

Notes: Extraction method: principal component analysis. Rotation method: Varimax with Kaiser normalization.

Three items loaded on the first factor and explained 31\% of the variance with Cronbach's $\alpha=0.55$. The second factor comprised three items and explained $21 \%$ of the variance. Cronbach's $\alpha$ was 0.51 for items of the second factor. Tetlock stated a Cronbach's $\alpha$ of 0.81 for his hedgehog-fox factor (Tetlock 2005, p. 241). However, he does not report on the reliability of his second factor, 'decisiveness.'

As expected, a differing factorial structure from Tetlock's one-dimensional solution was obtained consistently across our three studies. Consequently, there is a drop in the number of items loading uniquely on a factor. The number of items squared is an essential part of Cronbach's equation, which favors multi-item scales (Cortina 1993). Scales with fewer items obtain lower values of Cronbach's $\alpha$. To adequately address the challenge of more factors in the same pool of items, a set of three standards served as minimum criteria: (1) at least three items should inform one factor (Streiner 1994); (2) the Eigenvalues of the accumulated factors should account for at least $50 \%$ of the variance (Streiner 1994); and (3) values of Cronbach's $\alpha$ of 0.40 might be adequate in two- or three-item instruments (Peter 1997). Despite the reduction, all three standards are met. Therefore, we assume our Cronbach's $\alpha$ exceeding 0.50 is acceptable. We further address this issue in the discussion.

The CFA results showed that the two-factor model with six items is statistically and methodologically supported and was preferable to the one-factor model (Table 5). Although the 
two factors that significantly correlate with each other $(r=0.20, p<0.01$ for subsample 2) can be seen as separate constructs, each is composed of three items from different subdimensions of Kruglanski's NFCS: the three foxiness items from the facet closed-mindedness (reversed), and the three hedgehogness items from the facets discomfort with ambiguity, decisiveness, and preference for order.

Table 5. Results of Confirmatory Factor Analysis (Six Items), AMOS Model Fit Indices.

\begin{tabular}{ccccccc}
\hline Model & Description & $\chi^{2}$ & df & $\chi^{2} / \mathbf{d f}$ & RMSEA & CFI \\
\hline Study 1 & & & & & & \\
Model 1 & One-factor model & $184.51^{* *}$ & 7 & 26.36 & 0.11 & 0.83 \\
Model 2 & Two-factor model & $26.75^{* *}$ & 6 & 4.46 & 0.04 & 0.98 \\
Study 2 $^{2}$ & Two-factor model & $81.78^{* *}$ & 6 & 13.63 & 0.05 & 0.97 \\
Study 3 $^{3}$ & Two-factor model & $62.10^{* *}$ & 6 & 10.35 & 0.04 & 0.98 \\
\hline
\end{tabular}

Notes: ${ }^{1} n=2245$ (Subsample 2); ${ }^{2} n=5052 ;{ }^{3} n=7802$; Root Mean Square Error of Approximation; CFI = comparative fit index. ${ }^{*} p<0.01$.

Neuberg et al. (1997) have highlighted the construct's multifactorial structure in contrast to an overall score interpretation. They also find two epistemic motives in the NFCS that support our solution, although these motives differ slightly from the current interpretation. In our revision with a population-representative sample, Tetlock's items did not contribute to an unambiguous factor solution. Previously interpreted as the end points of a continuum, our large-scale inquiry revealed that foxes and hedgehogs are distinct factors. We termed these factors hedgehogness and foxiness ${ }^{1}$.

(1) The hedgehogness factor

This factor is characterized by a clear and ordered worldview with coherent organizing principles. Clear rules-often highly complex-govern action and decision-making. This conviction of knowing the world may indicate an ability to develop big vision and strong ideas, but may point to a fairly mechanistic conception of the world, which is classifiable and ultimately manageable. In this sense, hedgehogness is represented by one overarching coordinating system instead of scattered value systems and paradigms. It is associated with confident decision-making and agency. However, downplaying and devaluing ambiguity may be associated with inappropriate information-processing and reluctance or even inability to incorporate new ideas and information into one's conceptual system. Low hedgehogness levels imply a lower need for structure and rules as well as for quick decisions.

(2) The foxiness factor

The foxiness factor's items reflect the need and ability to incorporate more than one worldview into one's reflections. Analyses are undertaken from different standpoints, acknowledging plurality and multiple truths. This can also be achieved in situations of conflict or crisis. Foxiness also refers to the ability to entertain oneself with different paradigms, even though an opinion has potentially been established or decision-making processes have progressed. Foxiness includes an openness to exposing oneself to new and even opposing ideas, and reflects a systemic and sometimes inconclusive perspective rather than a mechanistic perspective. The downside is that absorbing ambiguity and reaching cognitive overload may lead to confusion and inability to act. Low scorers on foxiness are less open to hear, get involved with, and accept different opinions.

We used Studies 2 and 3 to confirm the two-factor model with the hedgehogness factor and the foxiness factor, each composed of three items. Table 5 shows the three studies' fit indices.

1 We use "foxiness" in the formal sense to mean "like a fox." 
The distribution statistics of foxiness approached a Gaussian distribution of values of skewness and kurtosis close to zero, and both scales exhibited a flatter distribution (negative value of kurtosis) and were slightly skewed to the left (negative value of skewness).

Confirmatory factor analyses with the subsample of employees with a leadership responsibility obtained similar results in all three studies.

\subsection{Differences in Scores between Gender, Age Groups, and Job Level}

We conducted independent samples $t$-tests of gender and simple regression analyses for age to test for possible differences in scores on hedgehogness and foxiness.

Since the results are inconsistent regarding gender differences in cognitive style, we were interested in whether we could find any differences with respect to hedgehogness and foxiness, especially as earlier work has suggested analyzing individual differences in cognitive styles with respect to genetic factors (Goodenough and Witkin 1977).

We compared hedgehogness and foxiness scores between men and women. Table 6 shows the mean differences for men and women. In Studies 1 and 3, the $t$-tests of sex differences in terms of cognitive style indicated no significant differences between men and women regarding foxiness. Only the mean difference in Study 2 was significant $(p<0.10)$. However, differences for hedgehogness were significant in all three studies, with men showing higher hedgehogness scores than women. Cohen's $d$ to assess the effect sizes of the differences resulted in values below 0.20 , indicating small effects.

Table 6. Results of Independent Samples $t$-Tests of Hedgehogness and Foxiness Means of Men and Women.

\begin{tabular}{|c|c|c|c|c|c|c|c|c|c|c|c|c|c|c|c|}
\hline & \multicolumn{5}{|c|}{ Study $1^{1}$} & \multicolumn{5}{|c|}{ Study 2} & \multicolumn{5}{|c|}{ Study 3} \\
\hline & Men & Wo & men & & & Men & & men & & & Men & & Women & & \\
\hline & $\mathbf{M}$ & $\mathbf{M}$ & $t$ & df & $d$ & $\mathbf{M}$ & $\mathbf{M}$ & $t$ & df & $d$ & $\mathbf{M}$ & $\mathbf{M}$ & $t$ & df & $d$ \\
\hline $\mathrm{H}$ & $\begin{array}{l}4.58 \\
(0.91)\end{array}$ & $\begin{array}{l}4.48 \\
(0.89)\end{array}$ & $2.66^{*}$ & 2243 & 0.11 & $\begin{array}{l}4.63 \\
(0.89)\end{array}$ & $\begin{array}{l}4.48 \\
(0.90)\end{array}$ & $6.17^{* * *}$ & 5050 & 0.17 & $\begin{array}{l}4.86 \\
(0.81)\end{array}$ & $\begin{array}{l}4.78 \\
(0.85)\end{array}$ & $4.62 * * *$ & 7251 & 0.10 \\
\hline$n$ & 1088 & 1157 & & & & 2515 & 2537 & & & & 4240 & 3465 & & & \\
\hline F & $\begin{array}{l}4.13 \\
(0.86)\end{array}$ & $\begin{array}{l}4.11 \\
(0.81)\end{array}$ & $\begin{array}{l}0.44 \\
\text { n.s. }\end{array}$ & 2243 & & $\begin{array}{l}3.98 \\
(0.86)\end{array}$ & $\begin{array}{l}3.93 \\
(0.83)\end{array}$ & $1.77+$ & 5050 & 0.06 & $\begin{array}{l}4.13 \\
(0.86)\end{array}$ & $\begin{array}{l}4.12 \\
(0.82)\end{array}$ & 0.79 n.s. & 7399 & \\
\hline$n$ & 1088 & 1157 & & & & 2515 & 2537 & & & & 4188 & 3398 & & & \\
\hline
\end{tabular}

Second, we analyzed the influence of age on hedgehogness and foxiness scores. Simple linear regression analyses revealed a positive relationship between age and hedgehogness as well as age and foxiness. Age predicted 10\% of the variance in hedgehogness in Study $1(\mathrm{~F}(1,2243)=235.51$, $p<0.001) ; 8 \%$ of the variance in Study $2(\mathrm{~F}(1,5051)=449.18, p<0.001)$; and $6 \%$ of the variance in Study $3(\mathrm{~F}(1,7704)=509.09, p<0.001)$, which corresponds to medium effects.

With regard to foxiness, age predicted only $1 \%$ of the variance in Study $1(\mathrm{~F}(1,2244)=22.10$, $p<0.001) ; 0.02 \%$ in Study $2(\mathrm{~F}(1,5051)=12.40, p=<0.001)$; and $0.01 \%$ in Study $3(\mathrm{~F}(1,7585)=8.78$, $p<0.01)$. Tables 7 and 8 show the regression results for hedgehogness and foxiness across all three studies.

Table 7. Results of Linear Regression Analyses of Age Predicting Hedgehogness.

\begin{tabular}{|c|c|c|c|c|c|c|c|c|c|}
\hline & \multicolumn{3}{|c|}{ Study $1^{1}$} & \multicolumn{3}{|c|}{ Study 2} & \multicolumn{3}{|c|}{ Study 3} \\
\hline & B & $S E B$ & $\beta$ & B & $S E B$ & $\beta$ & $B$ & $S E B$ & $\beta$ \\
\hline Age & 0.02 & 0.00 & $0.31^{* * *}$ & 0.02 & 0.00 & $0.29^{* * *}$ & 0.23 & 0.01 & $0.25^{* *}$ \\
\hline $\mathrm{R}^{2}$ & 0.10 & & & 0.08 & & & 0.06 & & \\
\hline F & $235.51 * * *$ & & & $\underset{* * *}{449.18}$ & & & $509.09^{* * *}$ & & \\
\hline $\mathrm{N}$ & 2245 & & & 5052 & & & 7705 & & \\
\hline
\end{tabular}


Table 8. Results of Linear Regression Analyses of Age Predicting Foxiness.

\begin{tabular}{cccccccccc}
\hline & \multicolumn{3}{c}{ Study $\mathbf{1}^{\mathbf{1}}$} & \multicolumn{3}{c}{ Study 2 } & \multicolumn{3}{c}{ Study 3 } \\
\hline & $\boldsymbol{B}$ & SE $\boldsymbol{B}$ & $\boldsymbol{\beta}$ & $\boldsymbol{B}$ & SE B & $\boldsymbol{\beta}$ & $\boldsymbol{B}$ & SE B & $\boldsymbol{\beta}$ \\
\hline Age & 0.01 & 0.00 & $0.10^{* * *}$ & 0.00 & 0.00 & $0.05^{* * *}$ & 0.03 & 0.01 & $0.03^{* * *}$ \\
$\mathrm{R}^{2}$ & 0.01 & & & 0.00 & & & 0.00 & & \\
$\mathrm{~F}$ & $22.10^{* * *}$ & & & $12.40^{* * *}$ & & & $8.78^{* *}$ & & \\
$\mathrm{~N}$ & 2245 & & & 5052 & & & 7586 & \\
\hline
\end{tabular}

Notes: ${ }^{1}$ Subsample $2 ;{ }^{* *} p<0.01,{ }^{* * *}=p<0.001$.

Further, we investigated the relationship between job levels and cognitive style in Studies 1 to 3, comparing the mean scores of hedgehogness and foxiness. As prior research has reported that more than $60 \%$ of the top managers interviewed could be categorized as hedgehogs (Gomez and Meynhardt 2012) we assume higher hedgehogness scores for leaders. Again, we found significant differences in the hedgehogness scores between leaders and non-leaders but no consistent results between the two groups concerning the foxiness scores. Independent samples $t$-tests showed that working respondents with a leadership responsibility scored significantly higher on the hedgehogness dimension than individuals without a leadership responsibility (Table 9). Significant differences regarding the foxiness dimension were found only in the German sample in Study 3. In Studies 1 and 2, the Swiss samples did not show different scores regarding the foxiness dimension for people with and without a leadership responsibility. While effect sizes for the differences in hedgehogness scores between respondents with a leadership responsibility and those without were medium in all the studies, the effect sizes for the differences in foxiness scores in Study 3 were very small.

In two of the three studies, after controlling for age and gender, an analysis of the relationship between hedgehogness and leadership status revealed significant but small correlations (Study 1: $r=0.04, p=0.13$; Study 2: $r=-0.05, p<0.01$; Study 3: $r=-0.10, p<0.001$ ). In Studies 2 and 3 hedgehogness and leadership status were negatively correlated. However, given the large sample size and the small effect sizes these results should be considered with caution.

Table 9. Results of Independent Samples t-Tests of Hedgehogness and Foxiness Means of Respondents with and without Leadership Responsibility.

\begin{tabular}{|c|c|c|c|c|c|c|c|c|c|c|c|c|c|c|c|}
\hline & \multicolumn{5}{|c|}{ Study $1^{1}$} & \multicolumn{5}{|c|}{ Study 2} & \multicolumn{5}{|c|}{ Study 3} \\
\hline & LR & & o LR & & & LR & & Jo LR & & & LR & & o LR & & \\
\hline & $\mathbf{M}$ & $\mathbf{M}$ & $t$ & df & $d$ & $\mathbf{M}$ & $\mathbf{M}$ & $t$ & df & $d$ & $\mathbf{M}$ & $\mathbf{M}$ & $t$ & df & $d$ \\
\hline $\mathrm{H}$ & $\begin{array}{l}4.53 \\
(0.86)\end{array}$ & $\begin{array}{l}4.38 \\
(0.89)\end{array}$ & $-3.00^{* *}$ & 1324 & 0.26 & $\begin{array}{l}4.60 \\
(0.88)\end{array}$ & $\begin{array}{l}4.43 \\
(0.89)\end{array}$ & $5.54^{* * *}$ & 3273 & 0.19 & $\begin{array}{l}4.88 \\
(0.77)\end{array}$ & $\begin{array}{l}4.68 \\
(0.82)\end{array}$ & $7.89 * * *$ & 3609 & 0.25 \\
\hline $\mathrm{n}$ & 480 & 846 & & & & 1291 & 1984 & & & & 1647 & 2858 & & & \\
\hline F & $\begin{array}{l}4.07 \\
(0.82)\end{array}$ & $\begin{array}{l}4.07 \\
(0.80)\end{array}$ & $\begin{array}{c}-0.175 \\
\text { n.s. }\end{array}$ & 1324 & & $\begin{array}{l}3.94 \\
(0.83)\end{array}$ & $\begin{array}{l}3.90 \\
(0.81)\end{array}$ & 1.311 n.s. & 3273 & & $\begin{array}{l}4.16 \\
(0.81)\end{array}$ & $\begin{array}{l}4.09 \\
(0.80)\end{array}$ & $3.15^{* *}$ & 4433 & 0.08 \\
\hline $\mathrm{n}$ & 480 & 846 & & & & 1291 & 1984 & & & & 1634 & 2801 & & & \\
\hline
\end{tabular}

Notes: ${ }^{1}$ Subsample 2; $\mathrm{H}=$ hedgehogness; $\mathrm{F}=$ foxiness; $\mathrm{M}=$ mean, standard deviation in parentheses; $\mathrm{LR}=$ respondents with leadership responsibility; No LR = respondents with no leadership responsibility; $d=$ Cohen's $d ;{ }^{* *}=p<0.01,{ }^{* * *}=p<0.001$.

\subsection{Differences in Scores Concerning Public Value Assessments}

Gomez and Meynhardt (2012) study led us to the assumption that respondents who favor the foxiness pole of the cognitive style continuum consider more sources of information and also include contradictory information in their judgments. These characteristics would lead to more moderate public value evaluations, compared to respondents who favor the hedgehog pole. Since hedgehogs are supposed to favor one truth and to be closed to multiple viewpoints, we assumed more extreme 
responses. Given our response format $(1=$ disagree to $6=$ agree) with higher values indicating a higher approval, we would expect higher public value evaluations for hedgehogs.

We formed extreme groups ( $1 \mathrm{SD}$ above and below the mean values of hedgehogness and foxiness) and excluded respondents with mid-level manifestation of hedgehogness and foxiness to compare differences concerning public value evaluations of the employing organizations. As Table 10 shows, the comparisons between low and high scorers on the hedgehogness dimension revealed significant differences in Studies 2 and 3. Respondents with high hedgehogness scores rated the public value of their organization higher than respondents with low hedgehogness scores with regard to the overall public value and across each of the public value dimensions. The mean differences between low and high levels of foxiness were also significant in Study 2 and point in the same direction. However, in Study 3, the results of the comparison between low and high scorers on the foxiness dimension differ. We found no significant difference between low and high scorers with regard to their assessment of the public value dimension morality, while respondents with high levels of foxiness rated the other public value dimensions significantly higher.

Table 10. Results of Independent Samples $t$-Tests of Hedgehogness and Foxiness Means of Respondents for the Overall Public Value of the Employing Organization and Each Public Value Dimension.

\begin{tabular}{|c|c|c|c|c|c|c|c|c|c|c|c|}
\hline & & \multicolumn{5}{|c|}{ Study 2} & \multicolumn{5}{|c|}{ Study 3} \\
\hline & & \multicolumn{2}{|l|}{ Low } & \multicolumn{3}{|l|}{ High } & \multicolumn{2}{|l|}{ Low } & \multicolumn{2}{|l|}{ High } & \multirow[b]{2}{*}{$d$} \\
\hline & & $\mathbf{M}$ & $\mathbf{M}$ & $t$ & df & $d$ & $\mathbf{M}$ & $\mathbf{M}$ & $t$ & df & \\
\hline \multirow{4}{*}{$\begin{array}{l}\text { Public } \\
\text { Value }\end{array}$} & $\mathrm{H}$ & $\begin{array}{c}4.67 \\
(1.09)\end{array}$ & $\begin{array}{c}5.16 \\
(0.94)\end{array}$ & $-7.22^{* * *}$ & 870.59 & -0.48 & $\begin{array}{c}4.42 \\
(1.08)\end{array}$ & $\begin{array}{c}4.83 \\
(1.11)\end{array}$ & $-6.75^{* * *}$ & 1377 & -0.37 \\
\hline & $n$ & 448 & 436 & & & & 558 & 821 & & & \\
\hline & $\mathrm{F}$ & $\begin{array}{c}4.71 \\
(1.09)\end{array}$ & $\begin{array}{c}5.15 \\
(0.93)\end{array}$ & $-6.73^{* * *}$ & 989.55 & -0.78 & $\begin{array}{c}4.56 \\
(1.07)\end{array}$ & $\begin{array}{c}4.72 \\
(1.12)\end{array}$ & $-2.67^{* *}$ & 1267 & -0.15 \\
\hline & $n$ & 572 & 433 & & & & 507 & 762 & & & \\
\hline \multirow{3}{*}{$\begin{array}{l}\text { Task } \\
\text { fulfillment }\end{array}$} & $\mathrm{H}$ & $\begin{array}{c}5.00 \\
(1.01)\end{array}$ & $\begin{array}{c}5.41 \\
(0.89)\end{array}$ & $-6.39^{* * *}$ & 882 & -0.43 & $\begin{array}{c}4.82 \\
(1.06)\end{array}$ & $\begin{array}{c}5.22 \\
(1.09)\end{array}$ & $-6.85^{* * *}$ & 1422 & -0.37 \\
\hline & $n$ & 448 & 436 & & & & 579 & 845 & & & \\
\hline & F & $\begin{array}{c}5.05 \\
(1.08)\end{array}$ & $\begin{array}{c}5.35 \\
(0.93)\end{array}$ & $-4.59^{* * *}$ & 1003 & -0.30 & $\begin{array}{c}4.97 \\
(1.05)\end{array}$ & $\begin{array}{c}5.08 \\
(1.09)\end{array}$ & -1.96 * & 1308 & -0.10 \\
\hline & $n$ & 572 & 433 & & & & 525 & 785 & & & \\
\hline \multirow{4}{*}{$\begin{array}{l}\text { Social } \\
\text { cohesion }\end{array}$} & $\mathrm{H}$ & $\begin{array}{c}4.31 \\
(1.43)\end{array}$ & $\begin{array}{c}4.92 \\
(1.26)\end{array}$ & $-6.80^{* * *}$ & 873.80 & -0.45 & $\begin{array}{c}4.04 \\
(1.44)\end{array}$ & $\begin{array}{c}4.45 \\
(1.49)\end{array}$ & $-5.12^{* * *}$ & 1392 & -0.28 \\
\hline & $n$ & 448 & 436 & & & & 567 & 827 & & & \\
\hline & $\mathrm{F}$ & $\begin{array}{c}4.34 \\
(1.38)\end{array}$ & $\begin{array}{c}4.95 \\
(1.22)\end{array}$ & $-7.40^{* * *}$ & 979.59 & -0.47 & $\begin{array}{c}4.14 \\
(1.44)\end{array}$ & $\begin{array}{c}4.44 \\
(1.46)\end{array}$ & $-3.68^{* * *}$ & 1282 & -0.21 \\
\hline & $n$ & 572 & 433 & & & & 516 & 768 & & & \\
\hline \multirow{3}{*}{ Morality } & $\mathrm{H}$ & $\begin{array}{c}4.80 \\
(1.25)\end{array}$ & $\begin{array}{c}5.22 \\
(1.34)\end{array}$ & $-5.21^{* * *}$ & 878.10 & -0.32 & $\begin{array}{c}4.44 \\
(1.28)\end{array}$ & $\begin{array}{c}4.84 \\
(1.34)\end{array}$ & $-5.59^{* * *}$ & 1417 & -0.31 \\
\hline & $n$ & 448 & 436 & & & & 575 & 844 & & & \\
\hline & $\mathrm{F}$ & $\begin{array}{c}4.87 \\
(1.22)\end{array}$ & $\begin{array}{c}5.23 \\
(1.10)\end{array}$ & $-4.85^{* * *}$ & 973.43 & -0.31 & $\begin{array}{c}4.63 \\
(1.29)\end{array}$ & $\begin{array}{c}4.67 \\
(1.35)\end{array}$ & -0.47 n.s. & 1300 & - \\
\hline \multirow{5}{*}{$\begin{array}{l}\text { Quality } \\
\text { of life }\end{array}$} & $n$ & 572 & 433 & & & & 521 & 781 & & & \\
\hline & $\mathrm{H}$ & $\begin{array}{c}4.57 \\
(1.35)\end{array}$ & $\begin{array}{c}5.10 \\
(1.22)\end{array}$ & $-6.13^{* * *}$ & 876.90 & -0.41 & $\begin{array}{c}4.40 \\
(1.34)\end{array}$ & $\begin{array}{c}4.85 \\
(1.35)\end{array}$ & $-6.24^{* * *}$ & 1410 & -0.34 \\
\hline & $n$ & 448 & 436 & & & & 572 & 840 & & & \\
\hline & $\mathrm{F}$ & $\begin{array}{c}4.59 \\
(1.35)\end{array}$ & $\begin{array}{c}5.08 \\
(1.16)\end{array}$ & $-6.17^{* * *}$ & 986.37 & -0.39 & $\begin{array}{c}4.48 \\
(1.39)\end{array}$ & $\begin{array}{c}4.74 \\
(1.34)\end{array}$ & $-3.29^{* *}$ & 1298 & -0.19 \\
\hline & $n$ & 572 & 433 & & & & 520 & 780 & & & \\
\hline
\end{tabular}

Notes: $\mathrm{H}=$ hedgehogness; $\mathrm{F}=$ foxiness; $\mathrm{M}=$ mean, standard deviation in parentheses; $d=\mathrm{Cohen}$ 's $d ;{ }^{*}=p \leq 0.05$, ** $=p<0.01,{ }^{* * *}=p<0.001$.

Table 11 shows mean differences and standard deviations for the public value assessments across the four groups in Studies 2 and 3. In Study 2, the independent samples $t$-test showed no significant differences between foxes (high foxiness, low hedgehogness) and hedgehogs (low foxiness, high hedgehogness) $(t(111)=0.41, p=0.68)$. However, in Study 3 , we observed significant differences between foxes and hedgehogs, with hedgehogs demonstrating significantly higher public value ratings than foxes $(t(163)=3.42, p<0.001$, Cohen's $d=0.55)$. Respondents with low scores on both dimensions showed significantly lower public value ratings than respondents with high scores on both dimensions (Study 2: $t(199)=-6.67, p<0.001$, Cohen's $d=0.88$, Study 3: $t(321)=-3.26, p<0.001$, Cohen's $d=0.42$ ). 
Table 11. Means of Public Value of Employing Organization for Groups with High and Low Levels of Foxiness and Hedgehogness.

\begin{tabular}{cccccccc}
\hline & \multicolumn{3}{c}{ Study 2 } & \multicolumn{3}{c}{ Study 3 } \\
\hline F & H & $\boldsymbol{n}$ & $\mathbf{M}$ & SD & $\boldsymbol{n}$ & $\mathbf{M}$ & SD \\
\hline Low & Low & 112 & 4.39 & 1.20 & 84 & 4.40 & 1.16 \\
Low & High & 69 & 4.91 & 1.17 & 97 & 5.09 & 0.89 \\
High & Low & 44 & 4.82 & 1.11 & 68 & 4.55 & 1.12 \\
High & High & 132 & 5.30 & 0.87 & 239 & 4.88 & 1.14 \\
\hline \multicolumn{3}{l}{ Notes: $\mathrm{H}$ = hedgehogness; F = foxiness; M = mean, SD = standard deviation. }
\end{tabular}

\section{Discussion}

\subsection{Theoretical Considerations}

All three studies support a two-factor solution, reflecting (1) a factor called hedgehogness and (2) a factor called foxiness. Individuals can achieve scores simultaneously on each of the two dimensions. Scoring high on the hedgehogness dimension indicates an individual preference for efficient goal attainment, clear rules, and fast and confident judgment and decision-making. High scores on the foxiness dimension imply individual tolerance for ambiguity and the active seeking out of different opinions.

Our revision of Tetlock's work is an attempt to widen its current interpretation, and our investigation reveals important considerations of the construct's nature. Of interest is that, in contrast to our two-factor solution, Tetlock's unifactorial solution claims a continuum between foxiness and hedgehogness. Ironically, our research supports Berlin's observation that Tolstoy "was by nature a fox, but believed in being a hedgehog" (Berlin 1997, p. 438).

Tetlock admits that his scale is "a fuzzy measurement continuum" and also follows Berlin in recognizing "that few fit the ideal-type template of fox or hedgehog. Most of us are hybrids, awkward hedge-fox and fox-hog amalgams" (Tetlock 2005, p. 87). Further, he outlines anecdotal evidence from his own research, in which archetypically diagnosed foxes produce hedgehog-like arguments in conversations. Instead of drawing distinct concepts from these observations, Tetlock argues, "I should not fall into the essentialist trap of viewing 'hedgehogs' and 'foxes' as distinct cognitive species" (Tetlock 2005, p. 87).

While for Tetlock high foxiness is the same as low hedgehogness and intrapersonal flexibility is understood as moving up and down the continuum at the expense of one end or the other, our survey data show a different picture. In contrast to Tetlock's selected sample of political experts, we used three studies with large samples that were representative for Germany and the German-speaking area of Switzerland. Thus, our results can be generalized for individuals across various industries and different educational backgrounds.

Our data indicate the simultaneous existence of seemingly opposing styles, like two different, partly independent dispositions to act. This difference is important since it implies a multidimensional perspective. Possessing characteristics on both dimensions might initially seem contradictory. However, some situations demand a specific way of perceiving and processing information. Experiences and environmental factors significantly influence the cognitive style that can be considered adequate for a situation (Kozhevnikov 2007). If this were not so, one could not explain the many options of intra-individual variation. For instance, one person may be high on both dimensions, and another may be low on both. Tetlock cannot explain this variance since, in his model, an increase in one direction is always at a corresponding decrease of the other. In the logic of Tetlock's unidimensionality, a hybrid creature implies a middle position on the continuum and therefore low values for both orientations. In contrast, our hybridity logic allows for a strong fox and a strong hedgehog characteristic in one individual—even at the same time. 


\subsection{Differences in Hedgehogness Scores}

Our data showed significantly higher values for the hedgehogness factor for men and employees with a leadership responsibility. These findings correspond to results of prior research that classified the majority of the interviewed managers as hedgehogs (Gomez and Meynhardt 2012). Prior work also found cognitive style differences for women and individuals in a senior position: Women scored higher on the CSI, showing a stronger analysis orientation, whereas individuals in senior positions scored lower on the CSI and had higher values in their intuition orientation (Allinson and Hayes 1996). Other work also reported higher intuition values for top managers (Agor 1989). The question remains as to whether individuals with a leadership responsibility develop a preference for hedgehogness owing to their position's demands or whether their preference for hedgehogness has had an effect on being selected for a leadership responsibility (Hayes and Allinson 1998).

Our data reveal that age is a significant predictor of hedgehogness and foxiness, indicating higher values of hedgehogness with increasing age. However, while age could predict between $6 \%$ and $10 \%$ of the variance in hedghogness across all three studies, the effect concerning foxiness was only marginal and should be interpreted with caution.

Our results largely confirm our assumptions about cognitive style differences concerning public value assessments. Respondents with a clear preference for hedgehogness rated the public value of their employing firm higher than respondents with an explicit preference for foxiness. Participants that scored high on both factors gave their organizations the highest public value ratings.

\subsection{Dimension in Application}

A metaphor such as the hedgehog and the fox is easy to process (Hart and Long 2011), and its use is tempting. However, categorizations should be used with care, especially as they are often the basis for interventions. For instance, the underlying categories of the MBTI are still in use despite contradictory findings regarding the factorial structure (Carskadon 1979) and severe criticism of its predictive validity (Pittenger 1993). A vast industry with tools, certification programs, and consultancy services has developed around the MBTI. Eighty-nine Fortune 100 companies use the MBTI to maximize individual and team effectiveness across all job levels within companies (CPP 2017). Regardless of the mentioned findings, the MBTI categorizes individuals into mutually excluding categories and shapes the organizational realities of millions of people.

Bearing in mind the popularity and extensive use of the hedgehog-fox metaphor by many authors like Silver (2015), Collins (2001), Kay (2011), and Kahneman (2013), we should be critical about the foundation of metaphors and its use and be aware of its implications.

In line with Critical Management Studies, the current study widens the perspective of the hedgehog-fox metaphor in that it rejects a narrow description and clear-cut categories of individuals (Spicer et al. 2009). It lays a scientific foundation for a more ambivalent exploration of the metaphor and cognitive styles in general.

\subsection{Training in Cognitive Styles}

Cognitive style flexibility is becoming increasingly important in business and management (Kozhevnikov et al. 2014) and "[g]ood judgment now becomes a metacognitive skill" (Tetlock 2005, p. 23). Given that some individuals can develop metastyles that allow them to consciously switch between different cognitive styles, research is needed to establish the extent to which the flexibility to balance the two dimensions can be trained. In their book on developing management skills, Whetten and Cameron (2011) stress the importance of managers' self-awareness as a possible path to management effectiveness. They argue that self-awareness not only fosters the understanding and management of personal style preferences, but also increases managers' abilities to understand others' cognitive style preferences. Managers should be aware of the diversity of cognitive styles among their team members, because this diversity is essential for effective problem-solving and 
creative thinking. Importantly, team diversity may increase an organization's flexibility to react to changing environments (Jarzabkowski and Searle 2004). Heterogeneous team composition can also help to enhance collaboration and, ultimately, team performance. Hybrids might even make it possible to bridge the gap between more archetypically oriented foxes and hedgehogs.

Choosing the right combination of individuals with preferences for hedgehogness or foxiness should also be important for the development of new products and services. In the design thinking process, for example, the HedgeFox scale would allow for the optimal selection and constellation of team members. Especially in the early stages of the design thinking process, when it is important to broaden one's perspective and put oneself in the position of different consumers or stakeholders, individuals with preferences for foxiness should be integrated into the process since they are more likely to get themselves into the complexity of the problem. In the later stages of the design thinking process, when it becomes more important to narrow down opportunities and move into the implementation phase, teams benefit especially from individuals with preferences for hedgehogness.

Thus, sensitivity to individual style preferences may influence strategic decisions concerning staff selection and task assignment. Complementary to the tradition of person-environment fit research, jobs and tasks can be assessed according to cognitive styles affordances. A recent meta-analysis (Kristof-Brown et al. 2004) suggests high correlations of person-job-fit with job satisfaction and organizational commitment. Also, person-job-fit is significantly negatively related to turnover intention. Following our argumentation with regard to the oversimplified classification of people, the results of our analyses imply a liberating argumentation because they enlarge the opportunities from either/or to more diverse assignments of individuals to jobs or tasks.

Organizations benefit from the HedgeFox Scale because it makes transparent individual differences in the perception and processing of information, and can enhance the understanding of how people deal with problems. For instance, whether people strive for truth and best practice (hedgehog) or workable solutions and good practice (fox) constitutes a big difference.

A HedgeFox Scale assessment could suggest essentials for appropriate communication to better address people with different mindsets. Further, it could help reveal and discuss homogenous thought patterns in teams and could serve to encourage the acceptance of diverse points of view.

\subsection{Public Value}

Concerning the public value discourse, our results are an important step toward the microfoundation of public value. Furthermore, the studies pave the way for further inquiry into the drivers of public value perception, and particularly the investigation of whether organizations can develop strategies that resonate with both hedgehogs and foxes. It should be important to choose the right communication approach to address the needs of both target groups. But creating public value already starts with valuable products and services that can stand a public value assessment from both perspectives, for example by purposefully designing for public value hybridity according to our logic. A case in point is Apple, which has both a strong central hedgehog idea ("Everything we do, we believe in challenging the status quo") and a multi-dimensional fox-like public value proposition-i.e., a combination of functional, aesthetical, and even political values.

Interestingly, our studies can distinguish the manifestation of the public value based on the differences within a cognitive style. Conforming to the assumption that hedgehogs are following one central theme, higher manifestations of hedgehogness emphasize public value more strongly throughout all dimensions of the construct. With regard to foxiness, stronger manifestations of the style are also associated with a higher public value assessment. However, within the sub-dimensions, there are hints of a more diverse picture. For instance, while in Study 2 in the dimension of morality there was a significant difference between high and low foxiness, the public value of high foxiness is as low as that of low foxiness, while diverging strongly from high and low hedgehogness in Study 3. 


\subsection{Managerial Implications}

The low number of six items of the HedgeFox Scale allows for swift completion and a quick assessment of cognitive style preferences. Since we found that people with leadership responsibility showed higher scores on the hedgehogness factor, the instrument should be a promising tool for discovering individual differences in information-processing and judgment and decision-making. Unlike longer inventories, such as the Rational-Experiential Inventory (REI) (Epstein et al. 1996) and the Cognitive Style Indicator (CoSI) (Cools and van Den Broeck 2007), our HedgeFox Scale provides convenience in determining differences in judgment and decision-making behaviors. Awareness of cognitive style preferences is crucial for managers (Sadler-Smith 2004) as they must often provide expert judgment, which sometimes requires swift decision-making, and they need to be open to diverse opinions. Especially in top leadership positions, managers need to be able to deal with complex tasks and a variety of demands (Gomez and Meynhardt 2012). Thus, cognitive style flexibility is very relevant for managers. The HedgeFox Scale can help managers to reflect on the ways they tend to analyze and process information, and can enhance their self-awareness for individual style preferences.

\section{Limitations and Future Research}

Although our paper is based on three separate large-scale studies $(n=17,072)$ providing robust and replicated results, the investigation has some shortcomings. The studies reveal moderate values of Cronbach's $\alpha$ on both dimensions, with the foxiness factor reaching a relatively low value of 0.51. All three items of our foxiness factor comprise reversed-coded items of the NFCS facet of closed-mindedness. Kruglanski et al. (1997) have reported lower homogeneity of closed-mindedness for eight items, ranging between 0.51 and 0.63 in four samples. They argue that the lower homogeneity compared to the other NFCS facets could be explained by the naturally higher heterogeneity or by psychometric item characteristics. Our revised instrument is an economic scale that has the shortcoming of only moderate reliability. Particularly concerning differential diagnostics and convergent validation, longer scales are desirable. Future studies should develop additional items to increase the instrument's reliability and validity.

Analysis of the intra-individual stability of the scores in the hedgehogness and foxiness dimensions is another future research area. Individual styles could be modified by environmental factors, such as professional and sociocultural interactions (Kozhevnikov et al. 2014). If actively choosing between styles is possible, depending on the environment's demands, individuals with high self-awareness could be more likely to combine the two cognitive styles. This assumption is in line with the suggestion that self-awareness of one's cognitive style fosters metacognitive skills and thus leads to better dealing with emotions (Akinci and Sadler-Smith 2013). Applying a longitudinal study design, researchers should analyze how environmental factors lead to changes in preferences for each dimension on an intra-individual level and a group level. In this context, it would also be interesting to examine whether environmental or situational factors such as time pressure or work overload may impede the flexible use of cognitive styles.

Examining the relationships between the HedgeFox Scale and other cognitive style constructs will help in assessing the scale's convergent validity (Hodgkinson and Sadler-Smith 2003; Allinson and Hayes 1996). Individuals with a high need for closure are more likely to use stereotypes in their judgments (Dijksterhuis et al. 1996). Compared to rule-based, more analytic processing, heuristics-driven information processing is related to intuition (Kozhevnikov et al. 2014). We expect positive relationships between hedgehogness and the CSI dimension of intuition as well as foxiness and the analytic dimension of the CSI.

Further analyses should focus on the HedgeFox Scale's predictive validity concerning performance-related measures. It would be interesting to study the implications of cognitive style preferences concerning managerial behaviors, such as decision-making or conflict-handling. Further, studies could focus on the relationship between cognitive style diversity in teams and team performance. 
Furthermore, future research could examine whether there are cultural differences with regard to employee public value assessments. Systematic cultural differences might have implications for the sensitivity toward the public value perception of organizations and thus translate into behavior. The cross-cultural analyses of Hofstede (1983) and Schwartz and Bardi (2001) regarding value priorities across different cultures could serve as a starting point for this kind of investigation.

Our research might also contribute to the organizational ambidexterity research field. Exploration and exploitation as efficient and flexible modes of organizational action have been investigated across different industries and have been related to a broad array of success measures (O'Reilly and Tushman 2013). However, ambidexterity has merely been measured as a structural property of organizations. Very little research has addressed the individual foundation and measurement of ambidexterity (Raisch et al. 2009). For a more solid foundation rooted in individual cognition and action, it will be of great use to study the relationship between the cognitive style construct and ambidexterity measures such as the behavioral ambidexterity scale (Mom et al. 2009).

We expect positive relationships between exploration and foxiness as well as between exploitation and hedgehogness. The HedgeFox Scale might even contribute to a measure of cognitive ambidexterity.

Following this line of thought in the ambidexterity framework, an important investigation would examine whether the combination of some characteristics of foxiness and hedgehogness may be beneficial for better predicting future events, or-as the latest work by Tetlock suggests-to qualify as a superforecaster (Tetlock and Gardner 2016).

\section{Conclusions}

Our findings provide empirical evidence of individual differences in information processing and shed some light on the frequently used metaphor of the hedgehog and the fox. Contrary to Tetlock's initial study, we find evidence of a two-factor structure, indicating that individuals can simultaneously be high/low on both dimensions. We contribute to the debate on the conceptualization of cognitive styles by introducing the HedgeFox Scale. Our study calls for the appreciation of such a metaphorical categorization and reflection upon its limits.

Acknowledgments: We are grateful for encouraging and helpful comments by Philip E. Tetlock. We also want to thank the anonymous reviewers for their constructive remarks. Stefan Anderer wants to thank Friede-Springer-Foundation for the support of his research.

Author Contributions: Each co-author contributed to the writing of this paper. The research has been jointly designed, analyzed and written. All authors read and approved the final manuscript.

Conflicts of Interest: The authors declare no conflict of interest.

\section{References}

Agor, Weston H. 1989. The Logic of Intuitive Decision Making. A Research-Based Approach for Top Management. Westport: Quorum Books.

Akinci, Cinla, and Eugene Sadler-Smith. 2013. Assessing Individual Differences in Experiential (Intuitive) and Rational (Analytical) Cognitive Styles. International Journal of Selection and Assessment 21: 211-21. [CrossRef]

Allinson, Christopher W., and John Hayes. 1996. The Cognitive Style Index: A Measure of Intuition-Analysis for Organizational Research. Journal of Management Studies 33: 119-35. [CrossRef]

Armstrong, Steven J., Eva Cools, and Eugene Sadler-Smith. 2012. Role of Cognitive Styles in Business and Management: Reviewing 40 Years of Research. International Journal of Management Reviews 14: $238-62$. [CrossRef]

Baggozzi, Richard P., and You Jae Yi. 1998. On the Evaluation of Structural Equation Models. Journal of the Academy of Marketing Science 16: 74-94. [CrossRef]

Berlin, Isaiah. 1997. The Proper Study of Mankind. New York: Farrar, Straus \& Giroux.

Betsch, Cornelia, and Justus Kunz. 2008. Individual strategy preferences and decisional fit. Journal of Behavioral Decision Making 21: 532-55. [CrossRef] 
Briggs, Katharine, and Isabel Briggs Myers. 1995. (German version by Richard Bents and Rainer Blank); MBTI. Myers-Briggs Typenindikator. Manual. Göttingen: Beltz.

Brown, Timothy A. 2006. Confirmatory Factor Analysis for Applied Research. New York: Guilford Press.

Carskadon, Thomas G. 1979. Clinical and counseling aspects of the Myers-Briggs Type Indicator: A research review. Research in Psychological Type 2: 2-31.

Collins, Jim C. 2001. Good to Great. Why Some Companies Make the Leap ... and Others Don't, 1st ed. New York: HarperBusiness.

Cools, Eva, and Herman van Den Broeck. 2007. Development and Validation of the Cognitive Style Indicator. The Journal of Psychology 141: 359-87. [CrossRef] [PubMed]

Cortina, Jose M. 1993. What is coefficient alpha? An examination of theory and applications. Journal of Applied Psychology 78: 98-104. [CrossRef]

CPP. Quick Facts. Available online: https:/ / www.cpp.com/products/mbti/index.aspx (accessed on 25 July 2017).

Dijksterhuis, Ap, Ad van Knippenberg, Arie W. Kruglanski, and Carel Schaper. 1996. Motivated social cognition: Need for closure effects on memory and judgment. Journal of Experimental Social Psychology 32: 254-70. [CrossRef]

Epstein, Seymour. 2003. Cognitive-experiential self-theory of personality. In Handbook of Psychology. Edited by Irving B. Weiner, Donald K. Freedheim, John A. Schinka and Wayne F. Velicer. New York: Wiley, pp. 159-84.

Epstein, Seymour, Rosemary Pacini, Veronika Denes-Raj, and Harriet Heier. 1996. Individual differences in intuitive-experiential and analytical-rational thinking styles. Journal of Personality and Social Psychology 71: 390-405. [CrossRef] [PubMed]

Gomez, Peter, and Timo Meynhardt. 2012. More foxes in the boardroom: Systems thinking in action. In Systemic Management for Intelligent Organizations. Edited by Stefan N. Grösser and Rene Zeier. Berlin and Heidelberg: Springer, pp. 83-98.

Goodenough, Donald R., and Herman A. Witkin. 1977. Origins of the field-dependent and field-independent cognitive styles. ETS Research Report Series 1977: 1-80. [CrossRef]

Guttieri, Karen, Michael D. Wallace, and Peter Suedfeld. 1995. The integrative complexity of American decision makers in the Cuban Missile Crisis. Journal of Conflict Resolution 39: 595-621. [CrossRef]

Harkness, Janet A., and Alicia Schoua-Glusberg. 1998. Cross-Cultural Survey Equivalence. In Questionnaires in Translation. ZUMA-Nachrichten Spezial, 3, Cross-Cultural Survey Equivalence. Edited by Janet A. Harkness. Mannheim: ZUMA.

Harkness, Janet, Beth-Ellen Pennell, and Alisú Schoua-Glusberg. 2004. Survey Questionnaire Translation and Assessment. In Methods for Testing and Evaluating Survey Questionnaires. Edited by Stanley Presser, Jennifer M. Rothgeb, Mick P. Couper, Judith T. Lessler, Elizabeth Martin, Jean Martin and Eleanor Singer. Hoboken: Wiley-Interscience, pp. 453-73.

Hart, Kathleen Robin, and John H. Long. 2011. Animal Metaphors and Metaphorizing Animals: An Integrated Literary, Cognitive, and Evolutionary Analysis of Making and Partaking of Stories. Evoution Education and Outreach 4: 52-63. [CrossRef]

Hayes, John, and Christopher W. Allinson. 1994. Cognitive Style and its Relevance for Management Practice. British Journal of Management 5: 53-71. [CrossRef]

Hayes, John, and Christopher W. Allinson. 1998. Cognitive Style and the Theory and Practice of Individual and Collective Learning in Organizations. Human Relations 51: 847-71. [CrossRef]

Hodgkinson, Gerard P., and Eugene Sadler-Smith. 2003. Complex or unitary? A critique and empirical re-assessment of the Allinson-Hayes Cognitive Style Index. Journal of Organizational Psychology 76: 243-68. [CrossRef]

Hodgkinson, Gerard P., Eugene Sadler-Smith, Marta Sinclair, and Neal M. Ashkanasy. 2009. More than meets the eye?: Intuition and analysis revisited. Personality and Individual Differences 47: 342-46. [CrossRef]

Hofstede, Geert. 1983. National cultures in four dimensions: A research-based theory of cultural differences among nations. International Studies of Management and Organization 13: 46-74. [CrossRef]

Hooper, Daire, Joseph Coughlan, and Michael R. Mullen. 2008. Structural Equation Modelling: Guidelines for Determining Model Fit. Electronic Journal of Business Research Methods 6: 53-60.

Jarzabkowski, Paula, and Rosalind H. Searle. 2004. Harnessing Diversity and Collective Action in the Top Management Team. Long Range Planning 37: 399-419. [CrossRef]

Jung, Carl Gustav. 1923. Psychological Types. New York: Harcourt Brace. 
Kahneman, Daniel. 2013. Thcinking, Fast and Slow, 1st paperbak ed. New York: Farrar Straus and Giroux.

Kay, John A. 2011. Obliquity. Why Our Goals are Best Achieved Indirectly, paperback ed. London: Profile Books.

Kirton, Michael J. 1976. Adaptors and Innovators: A Description and Measure. Journal of Applied Psychology 61: 622-29. [CrossRef]

Kozhevnikov, Maria. 2007. Cognitive styles in the context of modern psychology: Toward an integrated framework of cognitive style. Psychological Bulletin 133: 464-81. [CrossRef] [PubMed]

Kozhevnikov, Maria, Carol Evans, and Stephen M. Kosslyn. 2014. Cognitive Style as Environmentally Sensitive Individual Differences in Cognition: A Modern Synthesis and Applications in Education, Business, and Management. Psychological Science in the Public Interest: A Journal of the American Psychological Society 15: 3-33. [CrossRef] [PubMed]

Kristof-Brown, Amy L., Ryan D. Zimmermann, and Erin C. Johnson. 2004. Consequences of individuals' fit at work: A meta-analysis of person-job, person-organization, person-group, and person-supervisor fit. Personnel Psychology 58: 281-342. [CrossRef]

Kruglanski, Arie W., Donna M. Webster, and Adena Klem. 1993. Motivated resistance and openness to persuasion in the presence or absence of prior information. Journal of Personality and Social Psychology 65: 861-76. [CrossRef] [PubMed]

Kruglanski, Arie W., M. Nadir Atash, Eraldo DeGrada, Lucia Mannetti, Antonio Pierro, and Donna M. Webster. 1997. Psychological Theory Testing Versus Psychometric Nay-Saying: Comment on Neuberg et al.'s (1997) Critique of the Need for Closure Scale. Journal of Personality and Social Psychology 73: 1005-16. [CrossRef] [PubMed]

Lakoff, George, and Mark Johnson. 2003. Metaphors We Live By. London: The University of Chicago Press.

LeFebvre, Rebecca, and Volker Franke. 2013. Culture Matters: Individualism vs. Collectivism in Conflict Decision-Making. Societies 3: 128-46. [CrossRef]

Mandelman, Samuel D., and Elena L. Grigorenko. 2011. The Etiology of Intellectual Styles: Contributions from Intelligence and Personality. In Handbook of Intellectual Styles: Preferences in Cognition, Learning, and Thinking. Edited by Robert J. Sternberg, Li Fang Zhang and Stephen Rayner. Berlin: Springer Publishing Company, pp. 89-107.

McDonald, Roderick P., and Moon-Ho Ringo Ho. 2002. Principles and practice in reporting structural equation analyses. Psychological Methods 7: 64-82. [CrossRef] [PubMed]

Meynhardt, Timo. 2009. Public value inside: What is public value creation? International Journal of Public Administration 32: 192-219. [CrossRef]

Meynhardt, Timo. 2015. Public value: Turning a conceptual framework into a scorecard. In Public Value and Public Administration. Edited by John M. Bryson, Barbara C. Crosby and Laura Bloomberg. Washington: Georgetown University Press, pp. 147-69.

Meynhardt, Timo, and Steffen Bartholomes. 2011. (De)Composing public value: In search of basic dimensions and common ground. International Public Management Journal 14: 284-308. [CrossRef]

Mitchell, Gregory, and Philip E. Tetlock. 2010. Cognitive Style and Judging. In The Psychology of Judicial Decision Making. Edited by David Klein and Gregory Mitchell. Oxford: Oxford University Press, pp. 279-84.

Mom, Tom J.M., Frans A. J. van den Bosch, and Henk W. Volberda. 2009. Understanding Variation in Managers' Ambidexterity: Investigating Direct and Interaction Effects of Formal Structural and Personal Coordination Mechanisms. Organization Science 20: 812-28. [CrossRef]

Moore, Mark Harrison. 1995. Creating Public Value: Strategic Management in Government. Cambridge: Harvard University Press.

Moskvina, Valentyna, and Maria Kozhevnikov. 2011. Determining Cognitive Styles: Historical Perspective and Directions for Further Research. In Style Differences in Cognition, Learning, and Management: Theory, Research, and Practice. Edited by Stephen Rayner and Eva Cools. New York: Routledge, pp. 19-31.

Neuberg, Steven L., Nicole T. Judice, and Stephen G. West. 1997. What the Need for Closure Scale Measures and What It Does Not: Toward Differentiating Among Related Epistemic Motives. Journal of Personality and Social Psychology 72: 1396-412. [CrossRef]

O’Reilly, Charles A., and Michael L. Tushman. 2013. Organizational Ambidexterity: Past, Present, and Future. Academy of Management Perspectives 27: 324-38. [CrossRef]

Peter, Sybille Isabelle. 1997. Kundenbindung als Marketingziel: Identifikation und Analyse Zentraler Determinanten. Wiesbaden: Springer. 
Pittenger, David J. 1993. Measuring the MBTI ... and coming up short. Journal of Career Planning and Employment 54: 48-52.

Public Value Atlas Germany. Available online: www.gemeinwohlatlas.de/en (accessed on 2 January 2017).

Public Value Atlas Switzerland. Available online: www.gemeinwohl.ch/en (accessed on 2 January 2017).

Puccio, Gerard J., Donald J. Treffinger, and Reginald J. Talbot. 1995. Exploratory examination of relationships between creativity styles and creative products. Creativity Research Journal 8: 157-72. [CrossRef]

Raisch, Sebastian, Julian Birkinshaw, Gilbert Probst, and Michael L. Tushman. 2009. Organizational Ambidexterity: Balancing Exploitation and Exploration for Sustained Performance. Organization Science 20: 685-95. [CrossRef]

Riding, Richard. 2011. The Nature and Effects of Cognitive Style. In Perspectives on Thinking, Learning, and Cognitive Styles. Edited by Robert J. Sternberg and Li Fang Zhang. New York: Routledge, pp. 47-72.

Rüegg-Stürm, Johannes. 2002. Das neue St. Galler Management-Modell. Grundkategorien einer integrierten Managementlehre. Der HSG-Ansatz. Bern: Haupt Verlag.

Sadler-Smith, Eugene. 2004. Cognitive Style and the Management of Small and Medium-Sized Enterprises. Organization Studies 25: 155-81. [CrossRef]

Sadler-Smith, Eugene, and Beryl Badger. 1998. Cognitive style, learning and innovation. Technology Analysis $\mathcal{E}$ Strategic Management 10: 247-66.

Schwartz, Shalom H., and Anat Bardi. 2001. Value hierarchies across cultures: Taking a similarities perspective. Journal of Cross-Cultural Psychology 32: 268-90. [CrossRef]

Silver, Nate. 2015. The Signal and the Noise. Why so Many Predictions Fail-But Some Don't. New York: Penguin Books.

Simon, Herbert A. 1987. Making Management Decisions: The Role of Intuition and Emotion. Academy of Management Executive 1: 57-64. [CrossRef]

Spicer, David P., and Eugene Sadler-Smith. 2005. An examination of the general decision making style questionnaire in two UK samples. Journal of Managerial Psych 20: 137-49. [CrossRef]

Spicer, Andre, Mats Alvesson, and Dan Kärreman. 2009. Critical performativity: The unfinished business of critical management studies. Human Relations 62: 537-560. [CrossRef]

Sternberg, Robert J., and Elena L. Grigorenko. 1997. Are cognitive styles still in style? American Psychologist 52: 700-12. [CrossRef]

Streiner, Davia L. 1994. Figuring out factors: The use and misuse of factor analysis. Research Methods in Psychiatry 39: 135-40. [CrossRef]

Tetlock, Philip E. 2000. Cognitive Biases and Organizational Correctives: Do Both Disease and Cure Depend on the Politics of the Beholder? Administrative Science Quarterly 45: 293-326. [CrossRef]

Tetlock, Philip E. 2005. Expert Political Judgment: How Good Is It? How Can We Know? Princeton: Princeton University Press.

Tetlock, Philip E., and Dan Gardner. 2016. Superforecasting. The Art and Science of Prediction. London: Random House Books.

Van Den Broeck, Herman, Karlien Vanderheyden, and Eva Cools. 2003. Linking Cognitive Styles and Values. Available online: https:/ / public.vlerick.com/Publications/e9598e99-69a9-e011-8a89-005056a635ed.pdf (accessed on 28 January 2017).

Walsh, James P. 1995. Managerial and Organizational Cognition: Notes from a Trip Down Memory Lane. Organization Science 6: 280-321. [CrossRef]

Wang, Yi, Scott Highhouse, Christopher J. Lake, Nicole L. Petersen, and Thaddeus B. Rada. 2017. Meta-analytic Investigations of the Relation between Intuition and Analysis. Journal of Behavioral Decision Making 30: 15-25. [CrossRef]

Webster, Donna M., and Arie W. Kruglanski. 1994. Individual differences in need for cognitive closure. Journal of Personality and Social Psychology 67: 1049-62. [CrossRef] [PubMed]

Whetten, David A., and Kim S. Cameron. 2011. Developing Management Skills. Upper Saddle River: Prentice-Hall/Pearson. 
Witkin, Herman A., Carol A. Moore, Donald R. Goodenough, and Patricia W. Cox. 1977. Field-Dependent and Field-Independent Cognitive Styles and Their Educational Implications. Review of Educational Research 47: 1-64. [CrossRef]

Zhang, Li-Fang, and Robert J. Sternberg. 2012. The Nature of Intellectual Styles. Hoboken: Taylor and Francis.

Zhang, Li Fang, Robert J. Sternberg, and Stephen Rayner. 2011. Intellectual Styles: Challenges, Milestones, and Agenda. In Handbook of Intellectual Styles: Preferences in Cognition, Learning, and Thinking. Edited by Robert J. Sternberg, Li Fang Zhang and Stephen Rayner. Berlin: Springer Publishing Company, pp. 1-20.

(C) 2017 by the authors. Licensee MDPI, Basel, Switzerland. This article is an open access article distributed under the terms and conditions of the Creative Commons Attribution (CC BY) license (http://creativecommons.org/licenses/by/4.0/). 